\title{
Development of MILIONCAST, an Improved Model for Predicting Downy Mildew Sporulation on Onions
}

\author{
Tijs Gilles, Kath Phelps, John P. Clarkson, and Roy Kennedy, Warwick HRI, Wellesbourne, Warwickshire CV35 \\ 9EF, UK
}

\begin{abstract}
Gilles, T., Phelps, K., Clarkson, J. P., and Kennedy, R. 2004. Development of MILIONCAST, an improved model for predicting downy mildew sporulation on onions. Plant Dis. 88:695-702.

The effects of temperature and relative humidity on Peronospora destructor sporulation on onion (Allium cepa) leaves were studied under controlled environmental conditions. Sporangia were produced most rapidly at 8 to $12^{\circ} \mathrm{C}$ after $5 \mathrm{~h}$ of high humidity during dark periods. The greatest number of sporangia was produced at $100 \%$ relative humidity $(\mathrm{RH})$, and sporulation decreased to almost nil when humidity decreased to $93 \% \mathrm{RH}$. A model, named MILIONCAST (an acronym for MILdew on onION foreCAST), was developed based on the data from these controlledenvironment studies to predict the rate of sporulation in relation to temperature and relative humidity. The accuracy of prediction of sporulation was evaluated by comparing predictions with observations of sporulation on infected plants in pots outdoors. The accuracy of MILIONCAST was compared with the accuracy of existing models based on DOWNCAST. MILIONCAST gave more correct predictions of sporulation than the DOWNCAST models and a random model. All models based on DOWNCAST were more accurate than the random model when compared on the basis of all predictions (including positive and negative predictions), but they gave fewer correct predictions of sporulation than the random model. De Visser's DOWNCAST and ONIMIL improved their accuracy of prediction of sporulation events when the threshold humidity for sporulation was reduced to $92 \% \mathrm{RH}$. The temporal pattern of predicted sporulation by MILIONCAST generally corresponded well to the pattern of sporulation observed on the outdoor potted plants at Wellesbourne, UK.
\end{abstract}

Additional keywords: disease forecasting, disease management, modeling, Peronosporales, spore production

Downy mildew (Peronospora destructor) is a common, geographically widespread (1), and serious disease on onion crops that can result in major yield losses in bulb and salad onions and in onion seed production. Actual yield losses in bulb onions of 60 to $75 \%$ have been recorded $(8,10)$. These losses mainly result from severe infections in bulb onion crops causing early defoliation, reduced bulb sizes, and poor storage quality of bulbs $(7,22)$. In salad onions, yield losses can be as high as $100 \%$, with whole crops being discarded as downy mildew symptoms make them unmarketable. Losses to seed production are frequently caused by the collapse of infected seed stalks and poor germination of seeds collected from infected stalks (24).

The control of downy mildew in onions relies mainly on the prophylactic application of fungicides, as frequently as every 10 days. However, to reduce the impact of

Corresponding author: T. Gilles

E-mail: Tijs.Gilles@warwick.ac.uk

Accepted for publication 30 January 2004.

Publication no. D-2004-0419-01R

(C) 2004 The American Phytopathological Society fungicides on the environment, integrated pest management (IPM) systems need to be developed. A reduction in the number of fungicide applications, while maintaining disease control, could be achieved by applying fungicides only at times when conditions are favorable for disease development. The times when large numbers of spores of $P$. destructor are produced are thought to be related to the times when disease spreads. Such a direct relationship between airborne spore numbers and disease spread has been proposed for airborne fungal pathogens (5) and has been found for Mycosphaerella brassicicola on Brussels sprouts (19). The production of spores of $P$. destructor occurs only at night and only during some nights when conditions are favorable. For example, sporulation was observed on 45 out of 119 nights by Jesperson and Sutton in Canada (18) and on 24 out of 40 nights by de Visser in the Netherlands (11). The amount of spores produced during a night may vary with environmental conditions. Information on when large quantities of spores are produced could help growers to identify periods when disease is likely to spread. However, besides information on sporulation, further information on when conditions are favorable to infection and the latent period of infection is also required before growers can decide on the best times to apply control measures. A complete onion downy mildew forecasting system would therefore comprise models predicting sporulation, infection, and latent period. This study focuses on the development of the sporulation model for such a forecasting system.

An understanding of how the environment affects sporulation could be used to predict sporulation. However, the effects of environmental factors on sporulation by $P$. destructor on onion plants are complex. Sporulation of $P$. destructor is a diurnal process, and both periods of light and darkness are required, even though sporulation only occurs in darkness $(27,28)$. High day temperatures exceeding 24 to $25^{\circ} \mathrm{C}$ or exceeding $27,28,29$, or $30^{\circ} \mathrm{C}$ for more than $8,6,4$, or $2 \mathrm{~h}$, respectively, were found to inhibit sporulation during subsequent nights $(11,14,23)$. At night, sporulation was found to occur only when humidity rose above 94 to $95 \% \mathrm{RH}$ and temperatures were between 4 and $24^{\circ} \mathrm{C}$. Studies by Hildebrand and Sutton suggested that a combination of night temperature, time of onset of high humidity, and duration of high humidity affected the quantity of sporangia produced $(14,15)$.

The findings of Hildebrand and Sutton $(14,15)$ led to the development of the DOWNCAST model (18), which predicts sporulation and infection events of $P$. destructor. DOWNCAST predicts sporulation, but cannot predict the quantity of sporangia produced. Tests of the model in Canada suggested it gave positive predictions of sporulation for 38 out of 45 nights when sporulation was observed (18). Observations of downy mildew on onion trap plants in Australia also suggested that the model could predict infection events (12), but the part of the model predicting sporulation was not explicitly tested. However, in field tests in the Netherlands, DOWNCAST gave positive predictions of sporulation for only 11 out of 24 nights when sporulation was observed (11). Thus, the model often failed to predict sporulation events in a northwest European maritime climate in which the weather conditions are highly variable. de Visser made some modifications to the DOWNCAST model that increased the number of positive predictions to 17 out of 24 nights when sporulation had occurred. Battilani and colleagues developed ONIMIL, a forecaster, which is also based on DOWNCAST, and which gives a quantitative prediction for 
sporulation (4). However, the DOWNCAST model modified by de Visser and the ONIMIL model have not been tested for their accuracy with independent observations of sporulation.

A new forecasting model is needed that can predict sporulation accurately under variable weather conditions, such as those occurring in the northwest European maritime climate. This study reports on controlled-environment experiments, investigating the effects of temperature and air humidity on production of $P$. destructor sporangia and the development of new models describing onion downy mildew sporulation. It compares the accuracy of prediction of sporulation by DOWNCAST, de Visser's modified version of DOWNCAST, and ONIMIL with new mathematical empirical models developed in this study.

\section{MATERIALS AND METHODS}

Plant material and $P$. destructor isolate. Onion (cv. Armstrong) was sown in seedling trays in a greenhouse at ca. 13 to $17^{\circ} \mathrm{C}$, and after 4 weeks the seedlings were transplanted into square 9-cm-diameter pots at four plants per pot and kept in the same greenhouse. After 12 to 14 weeks, the plants developed five to eight mature leaves and were inoculated with a suspension of $P$. destructor sporangia $\left(1 \times 10^{4}\right.$ sporangia per milliliter) and placed in a controlled environment cabinet (Sanyo 970; $12 \mathrm{~h}$ light/12 h dark cycle with 150 $\mu \mathrm{mol} \mathrm{m} \mathrm{m}^{-2} \mathrm{~s}^{-1}$ light intensity) at $12^{\circ} \mathrm{C}$. In the cabinet, leaf wetness was maintained for $48 \mathrm{~h}$ after inoculation by automatic spraying of fine water droplets for $12 \mathrm{~s}$ every 10 min to facilitate infection. The infected plants were kept in the cabinet at $12^{\circ} \mathrm{C}$ and $80 \%$ RH for 16 to 18 days until the period of latency of $P$. destructor had elapsed and the plants had become infectious (according to van Doorn 10 to 17 days are required for symptom expression at moderate temperatures [23]). These plants would sporulate when the appropriate conditions occurred. For controlled-environment studies investigating the effects of temperature and humidity on sporulation (see below), the $P$. destructor isolate was collected from a spring onion crop at Hampton Lucy near Warwick, UK, in September 2000. For the study of sporulation on outdoor potted plants during the 1999 season (see below), the $P$. destructor isolate was collected from an onion field crop at Warwick HRI in Wellesbourne near Warwick, UK, in 1998. Both isolates are stored as frozen sporangia on leaves at Warwick HRI.

Effect of temperature. Entire leaves of ca. $20 \mathrm{~cm}$ in length were removed from the infectious plants and placed in enclosed polythene bags $(33 \times 35 \mathrm{~cm}$; three leaves per bag) with wetted tissue paper to create high humidity environments. These polythene bags were then placed in controlledenvironment cabinets (Sanyo 970) running at constant temperatures of 5.4, 7.9, 11.7, $16.2,20.0$, or $24.1^{\circ} \mathrm{C}$ in continuous darkness. The bags were removed from the cabinets after $2,4,6,8,10$, or $11.5 \mathrm{~h}$ in experiment 1 and after $3,4,5,7,9$, or $11 \mathrm{~h}$ in experiment 2 . The temperature treatments were randomly allocated to six available cabinets. At each sample time, three replicate bags were taken from each cabinet, and the number of spores produced per three leaves was measured for each replicate.

Effect of air humidity. Leaf sections of infected onion plants were placed into small humidity chambers at 93, 94, 95, 96, $97,98,99$, or $100 \% \mathrm{RH}$. Infected leaves were collected that had a pale grayishyellow hue over their entire surface, which suggested that the entire leaves had been colonized by $P$. destructor. Each leaf was sectioned into eight pieces that were randomly divided over the eight humidity treatments, so that differences in sporulation between treatments were not an effect of differences in sporulation capacity between leaves. The humidity chambers were made from petri dishes $(9 \mathrm{~cm}$ diameter, 1.5 $\mathrm{cm}$ height) to which $2 \%$ water agar with different concentrations of $\mathrm{NaCl}$ was added (93\% RH, $120 \mathrm{~g} \mathrm{NaCl} /$ liter; 94\% $\mathrm{RH}, 104 \mathrm{~g} \mathrm{NaCl} /$ liter; 95\% RH, $87 \mathrm{~g}$ $\mathrm{NaCl} /$ liter; 96\% RH, 71 g NaCl/liter; 97\% $\mathrm{RH}, 53 \mathrm{~g} \mathrm{NaCl} /$ liter; 98\% RH, $36 \mathrm{~g}$ $\mathrm{NaCl} /$ liter; 99\% RH, $18 \mathrm{~g} \mathrm{NaCl} /$ liter; $100 \%$ RH, no salt added) (20). Within the humidity chambers, the layer of water agar was suspended above the leaf segments with no contact between leaf and agar. Six leaf segments were placed in each humidity chamber, with each humidity treatment replicated four times in experiment 3 and seven times in experiment 4 . The humidity chambers were placed in an incubator at $12^{\circ} \mathrm{C}$ in total darkness for $14 \mathrm{~h}$, and sporulation was measured.

Measurement of sporulation. The leaf samples were put into vials containing 5 $\mathrm{ml}$ of a $1 \%$ polyoxyethylenesorbitan monolaurate (Sigma, Poole, UK) and 20\% ethanol solution. The vials were shaken with a Spinmix tube shaker (Sanyo Gallenkamp PLC, Loughborough, UK) at full speed for $10 \mathrm{~s}$ to liberate the sporangia before the concentration of sporangia in suspension was measured using a hemacytometer (Mod-Fuch's Rosenthal, supplied by Weber Scientific International Ltd., Teddington, UK). For experiments 1 and 2, the number of sporangia produced on the three leaves in each sample was calculated. In experiments 3 and 4, sporulation was measured as the number of sporangia produced per area of leaf. The surface area of all the leaf segments was measured by longitudinally sectioning the tubular onion leaf segments to flatten the segments and placing an acetate sheet with a $2 \times 2 \mathrm{~mm}$ grid over the flattened leaf surfaces and counting the number of squares of the grid covering the leaf segments. The leaf sur- face areas varied between 42 and $80 \mathrm{~cm}^{2}$ and were on average $63 \mathrm{~cm}^{2}$. The number of sporangia produced per square centimeter of onion leaf was calculated from these measurements. These measurements of sporulation were scaled to values ranging between 0 and 1 by dividing each value for sporulation by the maximum value for sporulation in each experiment, which occurred at $100 \% \mathrm{RH}$ in both experiments.

Modeling effect of temperature. A model was fitted to controlled environment data to describe the effects of temperature on sporulation of $P$. destructor with time. $\log _{10}$-transformed means of the number of sporangia $(s)$ produced per three leaves with time ( $t$ in hours) were described by a Gompertz function:

$\log _{10}(s+1)=c \exp \{-\exp [-b(t-m)]\}$

where $c$ was the maximum number of sporangia (on a $\log _{10}$-scale) that was produced with time, $b$ described the rate of increase in sporulation with time, and $m$ was the time from the onset of high humidity to when $37 \%$ of the maximum number of spores have been produced, which is the point of inflection of the Gompertz curve. The Gompertz model was used instead of the logistic model, because it explained more of the variation in the sporulation data, which resulted in lower estimates of the standard error; and it described better the observed steep increase in spore production at the start of sporulation followed by a more gradual decline in sporulation increases until a plateau was reached. Within this Gompertz equation, $b$ was a constant (plotting $b$ against temperature suggested that $b$ was not affected by temperature), and $c$ and $m$ were described by functions of temperature $\left(T\right.$, in $\left.{ }^{\circ} \mathrm{C}\right)$ based on a gamma distribution function (21):

$$
\begin{gathered}
c=\frac{\gamma_{c} \alpha_{c}^{-\beta c} T^{\beta c-1} e^{\frac{-T}{\alpha_{c}}}}{\Gamma\left(\beta_{c}\right)} \\
m=\frac{\Gamma\left(\beta_{m}\right)}{\gamma_{m} \alpha_{m}^{-\beta_{m}} T^{\beta_{m-1}} e^{\frac{-T}{\alpha_{m}}}}
\end{gathered}
$$

where $\alpha_{c}$ and $\alpha_{m}$ are index parameters, $\beta_{c}$ and $\beta_{m}$ are shape parameters, and $\gamma_{c}$ and $\gamma_{m}$ are scale parameters, relating to $c$ and $m$, respectively, and $\Gamma\left(\beta_{i}\right)$ (i is $c$ or $m$ ) is a constant, the gamma function, derived from $\beta_{i}$. The advantage of these gamma distribution functions is that asymmetric dome-shaped relationships of $c$ or $m$ with temperature can be described by only three parameters. Equations 1 to 3 were fitted by using the FITNONLINEAR directive within Genstat 4.2 fifth edition (21).

Modeling effect of humidity. The data from the above-described controlled humidity experiments were used to describe sporulation as a function of air humidity. An exponential model was fitted with the FITNONLINEAR directive within Genstat 
(21) to describe relative sporulation $\left(s_{r}\right.$, fraction of maximum sporulation) in relation to relative air humidity ( $v$, in $\% \mathrm{RH})$ :

$s_{r}=(1-R)^{(100-v)}$

where parameter $R$ described the decrease in the fraction sporangial production for every $1 \%$ decrease in humidity from water vapor-saturated air $(100 \% \mathrm{RH})$. This equation explicitly implies that $s_{r}=1$ at $100 \%$ $\mathrm{RH}$, and this data point has, therefore, been excluded during fitting of this equation to get a true estimate of the standard error of $R$.

Development of MILIONCAST. A differential equation was derived from equation 1 to calculate the rate of increase in sporulation. Equation 1 was rewritten as

$$
s=\exp \left\langle c^{\prime} \exp \{-\exp [-b(t-m)]\}\right\rangle-1
$$

with

$$
c^{\prime}=\frac{1}{\log _{10}(e)} c
$$

( $e$ is the base value of the natural logarithm). The differential equation was derived from this equation by using computer program Mathematica version 3 (25):

$$
\frac{d s}{d t}=b c^{\prime} \exp \left\langle\begin{array}{l}
\exp \{-\exp [-b(t-m)]\} c^{\prime}- \\
\exp [-b(t-m)]-b(t-m)
\end{array}\right\rangle
$$

This differential equation calculated the hourly rate of increase in sporangia as a function of temperature $\left(r_{T}\right)$ :

$r_{T}=\frac{d s}{d t}$

Equation 6 was combined with equation 4 to obtain a single model describing the rate of sporulation $(S)$ in relation to temperature and air humidity. Equation 4 was derived from a controlled-environment experiment investigating the effects of air humidity at $12^{\circ} \mathrm{C}$, which is approximately the optimum temperature for $P$. destructor sporulation. Furthermore, $12^{\circ} \mathrm{C}$ was in the middle of the range of temperature treatments that were used in the experiments to evaluate the effects of temperature on sporulation. It was assumed that the relationship between humidity and spore production at $12^{\circ} \mathrm{C}$ is the same as at the other temperatures. Equation 4 was, therefore, combined with equation 6 :

$$
S=r_{T} s_{r}
$$

However, this did not take account of specific interactions that may occur between temperature and air humidity in affecting the rate of sporulation. Such interactions were not examined in this study to avoid a highly complex model.

A forecasting model was developed to predict sporulation of $P$. destructor by applying equation 7 . This model is henceforth named MILIONCAST, an acronym for MILdew on onION foreCAST. In MILIONCAST, temperature and RH data, which were measured at 10 -min intervals, were input into equation 7 to calculate sporulation for each 10-min interval. These were summed to give the total predicted sporulation during a night. There was some uncertainty about when sporangial development starts. In MILIONCAST1, sporangial development was assumed to start directly following the onset of darkness. This was based on previous findings that darkness is needed to initiate sporangial development $(13,27,28)$. Sunset was defined as the time when the sun had rotated to $6^{\circ}$ below the horizon. In MILIONCAST2, sporangial development was assumed to start and progress when humidity increased to or above $92 \% \mathrm{RH}$ during darkness. This assumption was based on findings from the controlled-environment experiments described in this paper that sporulation approaches nil when humidity decreased to $93 \% \mathrm{RH}$. Time was a modified time scale, which stopped when $\mathrm{RH}<$ 92\% (interruption in high $\mathrm{RH}$ ) and continued when $\mathrm{RH} \geq 92 \%$. In both MILIONCAST models, it was assumed that when spores are being produced in the morning, the change from dark to light would not immediately inhibit spore production. Therefore, sporulation rates were calculated until 0900 GMT.

Specification of other existing models. MILIONCAST1 and 2 were compared with other existing models, such as DOWNCAST (18), a modified version of DOWNCAST by de Visser (de Visser's DOWNCAST) (11), and ONIMIL (4) (Table 1). The MILIONCAST models were also compared with de Visser's DOWNCAST and ONIMIL with threshold humidity levels for sporulation reduced to $92 \%$ $\mathrm{RH}$. A random model was also included in order to test whether the models predicted sporulation correctly more often than random prediction. Random numbers between 0 and 1 were generated by Genstat. The model predicted sporulation if the random number was less than $5 / 12$, which represented the expected frequency of sporulation events that was observed in the outdoor plant experiment at Wellesbourne, UK (see below; on 50 out of 120 nights sporulation had been observed).

Testing of disease forecasting models. Onion cv. Armstrong plants were sown in compost in seedling trays in the greenhouse (minimum temperature $15^{\circ} \mathrm{C}$ ). After ca. 5 weeks, the seedlings (two- to threeleaf stage) were transplanted into square 9$\mathrm{cm}$-diameter pots (four plants per pot) in compost. Approximately 3 to 4 weeks after transplanting, the plants (four-leaf stage) were inoculated with a sporangial suspension of $P$. destructor $\left(3 \times 10^{4}\right.$ spores per

\begin{tabular}{|c|c|c|c|c|}
\hline Condition & Time & DOWNCAST & de Visser's DOWNCAST & ONIMIL \\
\hline 1 & $\begin{array}{l}0800 \text { to } 2000 \\
\text { preceding day }\end{array}$ & $T_{h} \leq 24^{\circ} \mathrm{C}^{\mathrm{z}}$ & $\begin{array}{l}T>27,>28,>29,>30^{\circ} \mathrm{C} \\
\text { for }<8,<6,<4 \text { or }<2 \mathrm{~h}, \text { resp. }\end{array}$ & $T_{m} \leq 24^{\circ} \mathrm{C}$ or $T>27,28$ or $29^{\circ} \mathrm{C}$ for $<8,<4$ or $<2 \mathrm{~h}$, resp. \\
\hline 2 & $\begin{array}{l}2000 \text { to } 0800 \\
\text { at night }\end{array}$ & $4^{\circ} \mathrm{C} \leq T_{h} \leq 24^{\circ} \mathrm{C}$ & $4^{\circ} \mathrm{C} \leq T_{h} \leq 24^{\circ} \mathrm{C}$ & $4^{\circ} \mathrm{C} \leq T_{h} \leq 24^{\circ} \mathrm{C}$ \\
\hline 3 & $\begin{array}{l}0100 \text { to } 0600 \\
\text { at night }\end{array}$ & No rainfall & Rainfall $\leq 0.2 \mathrm{~mm}$ & No rainfall \\
\hline 4 & $\begin{array}{l}0200 \text { to } 0600 \\
\text { at night }\end{array}$ & $\begin{array}{l}\mathrm{RH} \geq 95 \% \\
\text { without interruption }\end{array}$ & $\begin{array}{l}\mathrm{RH} \geq 94 \% \\
\text { without interruption }\end{array}$ & $\mathrm{RH} \geq 95 \%$ without interruption \\
\hline \multirow[t]{3}{*}{5} & \multirow[t]{3}{*}{$\begin{array}{l}2000 \text { to } 0800 \\
\text { at night }\end{array}$} & \multirow[t]{3}{*}{-} & \multirow{3}{*}{$\begin{array}{l}\text { Quantification of sporulation by } \\
\text { Table } 4 \text { in de Visser (1998) } \\
\text { based on } T \text { and onset of } \mathrm{RH} \geq \\
94 \% \text {. }\end{array}$} & $T_{\text {eq }}=\frac{\left(T_{m}-T_{\min }\right)}{\left(T_{\max }-T_{\min }\right)} ; T_{\min }=4^{\circ} \mathrm{C}, T_{\max }=26^{\circ} \mathrm{C}$ \\
\hline & & & & Sporulation $(s): s=\left[\alpha\left(T_{\mathrm{eq}}\right) b\left(1-T_{\mathrm{eq}}\right)\right]^{c}$ \\
\hline & & & & $\begin{array}{l}\text { The values for } a, b \text {, and } c \text { vary between } 6,7,8 \text { or } 9 \mathrm{~h} \text { of high } \\
\text { humidity (RH } \geq 95 \% \text {; see Fig. } 3 \text { in Battilani et al. (1996). } \\
s=0 \text { when } \mathrm{RH} \geq 95 \% \text { for }<6 \mathrm{~h}\end{array}$ \\
\hline \multirow{2}{*}{\multicolumn{2}{|c|}{$\begin{array}{l}\text { Sporulation output } \\
\text { Model described in: }\end{array}$}} & No or yes & $0,1,2$, or 3 & Range 0 to 1 \\
\hline & & Jesperson \& Sutton (1987) & de Visser (1998) & Battilani et al. (1996) \\
\hline
\end{tabular}
milliliter; ca. $100 \mathrm{ml}$ sprayed on 20 pots of

Table 1. Conditions required for sporulation of Peronospora destructor on onion leaves to be predicted by DOWNCAST, de Visser's DOWNCAST, and ONIMIL

\footnotetext{
${ }^{\mathrm{z}} T$, temperature; $T_{h}$, mean hourly temperature; $T_{m}$, mean temperature over a certain time period; $T_{\text {eq }}$, temperature equivalent (values range 0 to 1 ).
} 
plants) and kept for ca. $16 \mathrm{~h}$ overnight in a misting cabinet to allow infection to occur. The inoculated plants were kept in a greenhouse at ca. $15^{\circ} \mathrm{C}$ for 2 weeks, after which the latent period had elapsed and the plants would sporulate if the right conditions occurred. Onion seedlings were inoculated weekly to provide a continuous supply of infected plants. On 120 days between May and October 1999, three pots of plants were placed outdoors at 1200 GMT, and the percent leaf length with sporulation was assessed for each leaf the following morning. These values were averaged to give a percent sporulation for each night. A Rotronic temperature and humidity sensor (Rotronic Instruments Ltd., Crawley, UK), a Delta-T rain gauge (Delta-T Devices Ltd., Burwell, UK), and a Skye Instruments surface wetness sensor (Skye Instruments Ltd., Llandrindod Wells, UK) were connected to a Delta-T data logger, which recorded the weather data at 10-min intervals. The sensors were located adjacent to the onion plants. The 1999 season was divided into four periods, which differed in temperature and humidity conditions to create replicates: 1 May to 9 June, 8 July to 7 August, 8 August to 14 September, and 15 September to 29 October (Fig. 1). Sporulation was assessed on $33,32,32$, and 23 days in each period, respectively: 120 days in total.

Comparing model predictions. Sporulation was predicted in each of the four periods in 1999 by inputting the recorded weather data into DOWNCAST, de Vis-
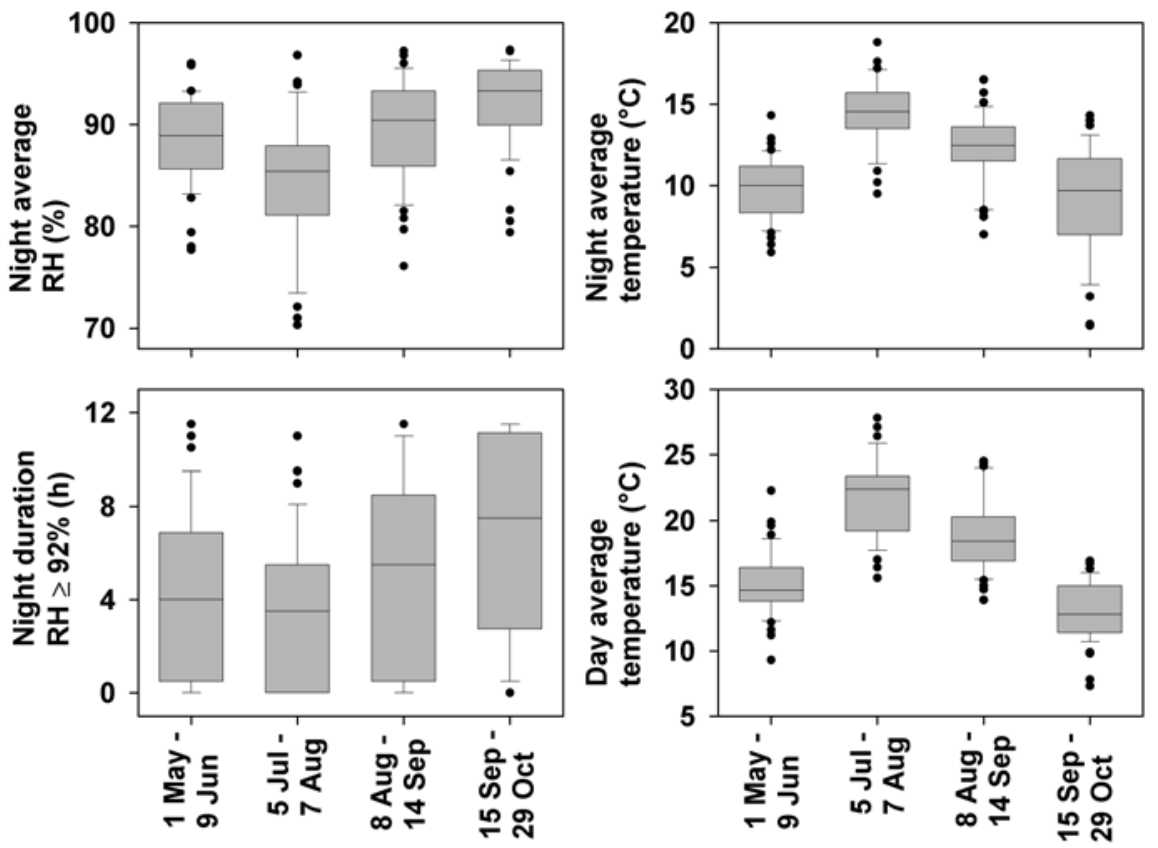

Period during 1999

Fig. 1. Box-plot graphs illustrating the variation in average relative humidity (RH in percent) during the night (between 2000 and 0800 GMT), duration of high humidity $(\mathrm{RH} \geq 92 \%)$ during the night, average night temperature (in ${ }^{\circ} \mathrm{C}$ ), and average day temperature (between 0800 and 2000 GMT) over four periods in the 1999 season at Wellesbourne, UK. The central line in each box is the median, each box spans from 25th to 75th percentile, and outer vertical lines span from 10th to 90th percentile. Black dots are data points that are outside the 10th and 90th percentile. total number of correct predictions of sporulation and no sporulation by the total number of nights in each period. Percent correct predictions of sporulation was calculated by dividing the number of correct predictions of sporulation by the sum of the total number of observations of sporulation and the number of false predictions of sporulation in each period. Similarly, percent correct predictions of no sporulation were calculated. The random model made predictions of sporulation for each period by repeating the random prediction 300 times and calculating the averages for percent correct prediction, percent correct prediction of sporulation, and percent correct prediction of no sporulation. Analysis of variance was done to estimate the mean values and the least significant differences of means (at $P=0.05$ ) of percent correct prediction, percent correct prediction of sporulation, and percent correct prediction of no sporulation. Furthermore, the conditions that were violated (resulting in false negative predictions) in the DOWNCAST-based models (i.e., sporulation occurred but was not predicted) were investigated to test the accuracy of the conditions specified in these models.

Accuracy of quantitative prediction. The accuracy of quantitative predictions by MILIONCAST1 and 2, de Visser's DOWNCAST, and ONIMIL models was tested by regressing predicted sporulation to observed values for percent leaf length with sporulation ( $\log _{10}$-transformed). The predictions of sporulation by MILIONCAST1 and 2 were $\log _{10}$-transformed.

\section{RESULTS}

Effect of temperature. Both the time to sporulation and the amount of sporangia produced were affected by temperature (Fig. 2). An optimum was found at 7.9 to $11.7^{\circ} \mathrm{C}$ where sporangia were first produced on the infected onion leaves after 5 $\mathrm{h}$ of high humidity. The time to first sporulation increased to $11 \mathrm{~h}$ as temperature increased to $24.1^{\circ} \mathrm{C}$ and increased to $9 \mathrm{~h}$ when temperature decreased to $5.4^{\circ} \mathrm{C}$. At $5.4^{\circ} \mathrm{C}$, less sporangia were produced.

Effect of air humidity. The greatest number of sporangia was produced at $100 \% \mathrm{RH}$ in both experiments (ca. 2 to $6 \times$ $10^{3}$ sporangia per $\mathrm{cm}^{2}$ leaf), and this number decreased when air humidity decreased to $93 \% \mathrm{RH}$ (ca. 50 to 100 sporangia per $\mathrm{cm}^{2}$ leaf) (Fig. 3). Sporulation was highly variable, and on average, greater numbers of sporangia per area of leaf were produced in experiment 4 than in experiment 3.

Modeling effects of temperature and humidity. The fitted Gompertz function (equation 1), with parameters $c$ and $m$ as gamma and inverse gamma distribution functions, respectively, of temperature (equations 2 and 3), described the data for sporulation with time generally well (Fig. 
2). However, the standard errors for parameters $\beta_{c}$ and $\gamma_{c}$ were large (Table 2), but this could be expected because at some of the temperatures maximum sporulation was not reached $\left(5.4,20.0\right.$, and $24.1^{\circ} \mathrm{C}$ ), resulting in estimates for $c$ being more variable. The fitted model overpredicted the time to sporulation at $7.9^{\circ} \mathrm{C}$ by ca. $1 \mathrm{~h}$ and underpredicted the time to sporulation at $16.2^{\circ} \mathrm{C}$ by ca. $0.5 \mathrm{~h}$. The exponential model (equation 4) fitted well to the data for sporulation in relation to humidity (Fig. 3 ) and gave an estimate of $R$ (Table 2).

Testing of disease forecasting models. Sporulation occurred on 50 out of 120 nights between May and October 1999 when infected plants were placed outdoors. On average, $81 \%$ of predictions by MILIONCAST2 were correct, and this model was more accurate than the DOWNCAST and ONIMIL models, which had 69 and $67 \%$ of predictions correct, respectively,

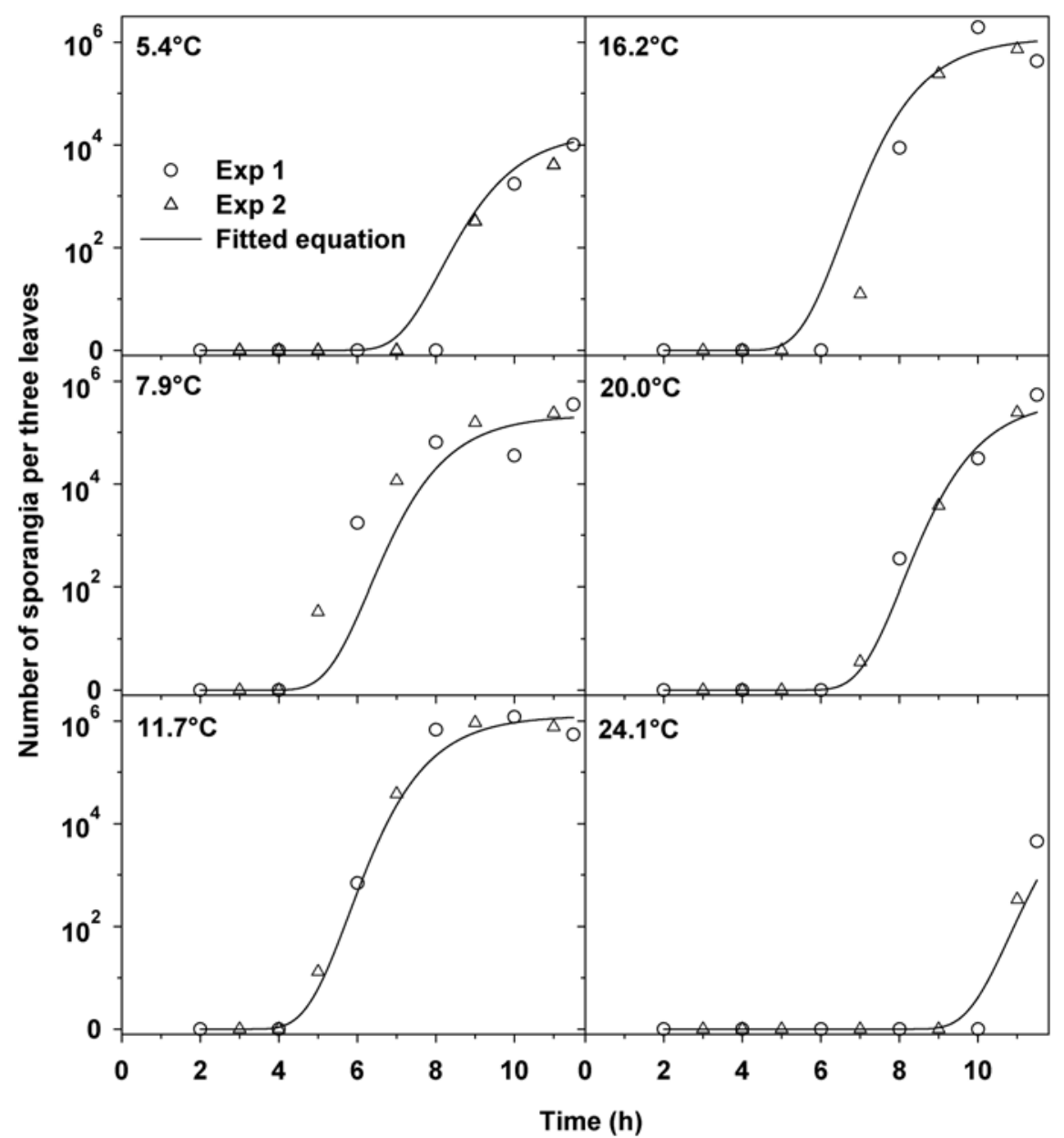

Fig. 2. Number of sporangia of Peronospora destructor produced per three onion leaves with time in experiments $1(\mathrm{O})$ and $2(\triangle)$ at temperatures ranging from 5.4 to $24.1^{\circ} \mathrm{C}$. Data points are averages of three replicate measurements. Gompertz curves were fitted to the data (equations 1 to 3; the fitted equations accounted for $95.2 \%$ of variance in data). but was not significantly better than de Visser's DOWNCAST, de Visser's DOWNCAST 92\%, and ONIMIL 92\% (Table 3). All models performed better than the random model, except for MILIONCAST1. DOWNCAST and ONIMIL had predicted only small numbers of the observed sporulation events and were not better than a random model in predicting sporulation. The modifications to DOWNCAST by de Visser increased the percent correct predictions of sporulation from 24 to $38 \%$, but not significantly more than by random prediction. By also reducing the threshold humidity for sporulation to $92 \%$ RH, de Visser's DOWNCAST and ONIMIL predicted sporulation more accurately than random prediction and were not significantly different from MILIONCAST2, which gave the highest percent correct predictions of sporulation, $61 \%$. These modifications had little effect on the number of false predictions. It was found that false negative predictions of sporulation (sporulation was observed, but not predicted) were often made as a result of violations of condition 4 in all DOWNCAST-based models (Tables 1 and 4). All

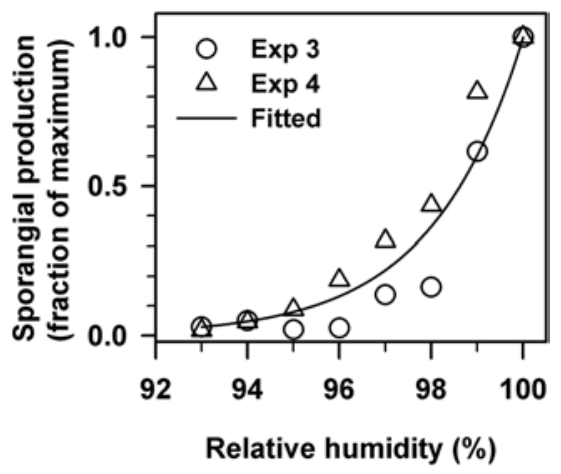

Fig. 3. Mean numbers of sporangia of Peronospora destructor on onion leaves on a 0 to 1 scale in experiments $3(O)$ and $4(\triangle)$ at different air humidities ranging from 93 to $100 \%$. An exponential function was fitted to the data to describe the fraction of sporangial production as a function of relative humidity (equation 4 ; the fitted equation accounted for $84.5 \%$ of variance in data).

Table 2. Parameter estimates and their standard errors obtained after fitting the model describing sporulation of Peronospora destructor on onion leaves as a temporal function of temperature (equations 1 to 3 ) and the model describing relative sporulation as a function of air humidity (equation 7)

\begin{tabular}{|c|c|c|c|c|}
\hline $\begin{array}{l}\text { Model } \\
\text { Sporulation }(s, \text { no. of sporangia per three leaves) as a } \\
\text { function of time }(t, \text { in } \mathrm{h}) \text { and temperature }\left(T, \text { in }{ }^{\circ} \mathrm{C}\right)\end{array}$ & \multirow{2}{*}{$\begin{array}{l}\text { Equation } \\
\log _{10}(s+1)=c \exp \{-\exp [-b(t-m)]\}\end{array}$} & \multirow{2}{*}{$\frac{\text { Parameter }}{b}$} & \multirow{2}{*}{$\begin{array}{r}\text { Estimate } \\
0.90\end{array}$} & \multirow{2}{*}{$\begin{array}{c}\text { SE } \\
0.123\end{array}$} \\
\hline \multirow{7}{*}{$\begin{array}{l}\text { Sporulation }(s, \text { no. of sporangia per three leaves) as a } \\
\text { function of time }(t, \text { in } \mathrm{h}) \text { and temperature }\left(T \text {, in }{ }^{\circ} \mathrm{C}\right)\end{array}$} & & & & \\
\hline & $\underline{-T}$ & $\alpha_{c}$ & 2.15 & 0.333 \\
\hline & $\gamma_{c} \alpha_{c}^{-\beta c} T^{\beta c-1} e^{\overline{\alpha_{c}}}$ & $\beta_{c}$ & 12.0 & 4.02 \\
\hline & $c=\frac{\tau\left(\beta_{c}\right)}{\Gamma}$ & $\gamma_{c}$ & 213 & 44.2 \\
\hline & $\Gamma\left(\beta_{m}\right)$ & $\alpha_{m}$ & 2.61 & 0.131 \\
\hline & $m=\frac{-T}{-T}$ & $\beta_{m}$ & 6.93 & 0.475 \\
\hline & $\gamma_{m} \alpha_{m}^{-\beta_{m}} T^{\beta_{m-1}} e^{\overline{\alpha_{m}}}$ & $\gamma_{m}$ & 4.01 & 0.090 \\
\hline $\begin{array}{l}\text { Relative sporulation }\left(s_{r} \text {, relative values between } 0\right. \\
\text { [=no sporulation] and } 1 \text { [=maximum sporulation] }) \\
\text { as a function of air humidity }(v \text {, in } \% \mathrm{RH})\end{array}$ & $s_{r}=(1-R)^{(100-v)}$ & $R$ & 0.40 & 0.031 \\
\hline
\end{tabular}


models predicted no sporulation events more accurately than the random model, except for MILIONCAST1.

Quantitative predictions of sporulation by all models explained little of the variation in observed sporulation. MILIONCAST2 and de Visser's DOWNCAST (with a 92\% RH threshold for sporulation) gave the best quantitative predictions of sporulation, with 48 and $43 \%$ of the variance explained by regression, respectively. Sporulation was always observed when MILIONCAST2 predicted more than $10^{4}$ sporangia per three leaves.

The temporal pattern of predicted sporulation by MILIONCAST2 generally compared well with the pattern of observed sporulation (Fig. 4). However, for some days in July (17, 18, 23, 29, and 30 July), sporulation was observed but not predicted, or very little was predicted. It was noted that during the nights preceding these days, surface wetness was recorded before a high RH was recorded by the data logger, which suggests that the $\mathrm{RH}$ recordings may have been inaccurate and that the recorded $\mathrm{RH}$ values were too low. It is evident that DOWNCAST, de Visser's
DOWNCAST (92\% RH), and ONIMIL (92\% RH) failed to predict sporulation for many nights when sporulation did occur. However, these models often predicted sporulation when large amounts of sporulation were observed.

\section{DISCUSSION}

The results of this study suggest that MILIONCAST can predict downy mildew sporulation in relation to temperature and relative humidity. Eighty-one percent of MILIONCAST predictions (this includes predictions of sporulation and no sporulation) were correct, which was better than by random prediction $(\approx 50 \%)$. The quantitative predictions by MILIONCAST gave guidance to the severity of sporulation, with high certainty of sporulation occurring when more than $10^{4}$ sporangia per three leaves were predicted. Furthermore, the observed temporal pattern of sporulation corresponded well with the temporal pattern of predicted sporulation by MILIONCAST in different periods within one season (1999). The MILIONCAST sporulation model has potential to become a useful tool in the management of downy

Table 3. Comparison of the accuracy of prediction of Peronospora destructor sporulation on outdoor onions between DOWNCAST-based models, MILIONCAST models, and a random model ${ }^{\mathrm{v}}$

\begin{tabular}{lccc}
\hline Model & $\begin{array}{c}\text { \% correct } \\
\text { predictions }^{\mathbf{w}}\end{array}$ & $\begin{array}{c}\text { \% correct pred. } \\
\text { sporulation }^{\mathbf{x}}\end{array}$ & $\begin{array}{c}\text { \% correct pred. } \\
\text { no sporulation }\end{array}$ \\
\hline Random model & $51 \mathrm{a}^{\mathrm{z}}$ & $25 \mathrm{a}$ & $41 \mathrm{~b}$ \\
DOWNCAST & $69 \mathrm{bc}$ & $24 \mathrm{a}$ & $64 \mathrm{c}$ \\
ONIMIL & $67 \mathrm{~b}$ & $19 \mathrm{a}$ & $63 \mathrm{c}$ \\
de Visser's DOWNCAST & $74 \mathrm{bcd}$ & $38 \mathrm{ab}$ & $68 \mathrm{c}$ \\
de Visser's DOWNCAST 92\% & $79 \mathrm{~cd}$ & $51 \mathrm{bc}$ & $72 \mathrm{c}$ \\
ONIMIL 92\% & $76 \mathrm{bcd}$ & $45 \mathrm{bc}$ & $69 \mathrm{c}$ \\
MILIONCAST1 & $49 \mathrm{a}$ & $46 \mathrm{bc}$ & $11 \mathrm{a}$ \\
MILIONCAST2 & $81 \mathrm{~d}$ & $61 \mathrm{c}$ & $72 \mathrm{c}$ \\
LSD (0.05)(21 df) & 11.0 & 19.7 & 9.6 \\
\hline
\end{tabular}

${ }^{\mathrm{v}}$ Mean values over four periods in the 1999 season are shown. The periods used were: 1 May to 9 June, 5 July to 7 August, 8 August to 14 September and 15 September to 29 October (see Fig. 1).

w \% correct predictions is calculated as the total number of positive predictions of sporulation and no sporulation events divided by the total number of predictions.

$\mathrm{x} \%$ correct predicted sporulation is calculated as the number of positive predictions of sporulation divided by the sum of the number of observed sporulation events and the number of false predictions of sporulation.

y $\%$ correct predicted no sporulation is calculated as the number of positive predictions of no sporulation divided by the sum of the number of observed no sporulation events and the number of false predictions of no sporulation.

${ }^{\mathrm{z}}$ The lettering indicates the significance of differences in means between models. A different letter indicates a significant difference, whereas the same letter indicates that these means are not significantly different.

Table 4. Conditions in the DOWNCAST-based models that were violated and resulted in false negative predictions of Peronospora destructor sporulation on onions over a period of 120 nights when sporulation was monitored between May and October 1999 at Wellesbourne, UK

Times a condition was violated

resulting in false negative prediction of sporulation

\begin{tabular}{lccccc}
\cline { 2 - 6 } Condition & DOWNCAST & $\begin{array}{c}\text { de Visser's } \\
\text { DOWNCAST }\end{array}$ & $\begin{array}{c}\text { de Visser's } \\
\text { DOWNCAST 92\% }\end{array}$ & ONIMIL & $\begin{array}{c}\text { ONIMIL } \\
\mathbf{9 2 \%}\end{array}$ \\
\hline 1 & 7 & 0 & 0 & 0 & 0 \\
2 & 2 & 2 & 2 & 2 & 2 \\
3 & 5 & 2 & 2 & 5 & 5 \\
4 & 29 & 23 & 16 & 29 & 16 \\
5 & $-\mathrm{z}$ & 1 & 2 & 5 & 4 \\
\hline
\end{tabular}

${ }^{\mathrm{z}}$ DOWNCAST does not have a fifth condition. mildew in onion crops when it is used in combination with infection models.

The accuracy of MILIONCAST improved greatly by changing the conditions that were assumed to cause the onset of sporulation from the onset of darkness following sunset to the onset of high humidity ( $\mathrm{RH} \geq 92 \%$ ) during darkness. This suggests that sporangial development does not occur during periods of darkness when the relative air humidity is too low, but further studies are required to provide evidence for this. Similarly, airborne spores of Bremia lactucae were only observed following periods when RH had increased above $95 \%$ during a night (6). Clearly, the method of implementation of models derived from controlled-environment experiments can have major implications on their success in predicting events that occur under natural conditions.

Several further improvements can be made to MILIONCAST. The effects of interactions between temperature and $\mathrm{RH}$ on the rate of spore production are not included in this model, and further experimental work may be necessary to study such interactions. Furthermore, it has been reported in other studies that high temperatures during the day affect sporulation the following night (14). These effects have not been included in this model. High day temperatures may indirectly reduce spore production as a result of water stress in infected onion plants, as was found for Peronospora tabacina on tobacco (9). A weakness of the model is that it is dependent on measurements of relative air humidity, which often have considerable errors when the amount of water vapor in the air is near saturation, to determine the onset of model calculations and to calculate the amount of sporangia produced. The error of the $\mathrm{RH}$ reading with the type of sensors commonly used can be as high as \pm 2 to $4 \%$ $(2,3)$.

It would be highly advantageous if the quantitative model for sporulation could be applied worldwide in regions where onions are grown, because $P$. destructor is such a geographically widespread pathogen (1). However, the conditions under which the pathogen produces sporangia may vary between strains from different geographical locations. Evidence that pathogens can adapt to different environments was found for Verticillium albo-atrum on alfalfa. Isolates of V. albo-atrum collected from southern Californian desert regions were found to have different growth and survival relationships with temperature than isolates collected from Europe and the northern United States (16). If such variation in environmental responses between strains of $P$. destructor from different regions exists, then MILIONCAST will not be widely applicable and different parameter estimates need to be obtained for each region to adapt the model accordingly. Sporulation may also be affected by inter- 
actions between cultivars and pathogen strains. For example, differences were found in the quantity of sporangia produced between different broccoli lines infected with Peronospora parasitica (17). The number of sporangia predicted by MILIONCAST is, therefore, only a value for the potential of $P$. destructor to sporulate during a night. The actual numbers of spores produced during a night is dependent on the level of infection and may vary among cultivars and $P$. destructor strains. MILIONCAST needs to be tested under different climates and locations, for different cultivars and seasons, to assess the accuracy of the model under varying circumstances.

The results of this study confirm findings by de Visser (11) that DOWNCAST gives poor predictions of sporulation in a northwest European maritime climate where weather conditions are often highly variable. DOWNCAST, de Visser's DOWNCAST, and ONIMIL did not predict sporulation more often than a random model, but often predicted sporulation when large amounts of sporulation were observed. Thus, they seem to be capable of identifying the nights when conditions are highly favorable for sporulation, but fail to predict many other nights when sporangia are also produced. The DOWNCAST- based models often failed to predict sporulation because of their specific time-bound statement that sporulation only occurs when $\mathrm{RH} \geq 94$ to $95 \%$ between 2:00 and 6:00 A.M. (condition 4, Table 1). Present observations of sporulation on infected outdoor onion plants suggested that $P$. destructor can produce sporangia when humidity is high for a sufficient length of time regardless of when this occurred at night.

MILIONCAST2 could become a useful tool as part of a forecasting system for onion downy mildew, which would also include models to predict infection and the latent period of infection. MILIONCAST2 is capable of predicting sporulation from temperature and air humidity readings at frequent intervals, and its predictions could contribute to effective timing of fungicide applications. The model is likely to be most useful for timing the application of systemic fungicides, of which often only a limited number of applications are allowed, because it predicts sporulation just after it has occurred, rendering contact fungicides less effective. There may be opportunities to use forecasted temperature and $\mathrm{RH}$ data as input to get an earlier prediction, but this will result in compounded errors. Field tests need to be conducted to evaluate if the proposed forecasting system can reduce the number of fungicide applications while maintaining effective disease control. In field trials in New Zealand, savings in fungicide applications were achieved by spraying according to DOWNCAST predictions (26), and the level of downy mildew control was not different from plots sprayed every 7 to 14 days.

\section{ACKNOWLEDGMENTS}

We thank the UK Department for Environment, Food and Rural Affairs (DEFRA) for financially supporting project HH1742SFV.

\section{LITERATURE CITED}

1. Anonymous. 1978. Distribution maps of plant diseases, map no. 76, Peronospora destructor (Berk.) Casp. 4th ed. CMI, Kew, UK.

2. Anonymous. 1999. Smaartlog. Meteorological monitoring station. Aardware Design, Walton on Thames, UK.

3. Anonymous. 2000. Technical data/Operating instructions H290B. Rotronic ag, Bassersdorf, Switzerland.

4. Battilani, P., Rossi, V., Racca, P., and Giosuè, S. 1996. ONIMIL, a forecaster for primary infection of downy mildew of onion. Eur. Mediterr. Plant Prot. Org. Bull. 26:567-576.

5. Campbell, C. L., and Madden, L. V. 1990 Introduction to Plant Disease Epidemiology. John Wiley \& Sons, New York.

6. Carisse, O., and Philion, V. 2002. Meteorological factors affecting periodicity and concentration of airborne spores of Bremia lactucae. Can. J. Plant Pathol. 24:184-193.

7. Chupp, C., and Sherf, A. F. 1960. Onion dis-
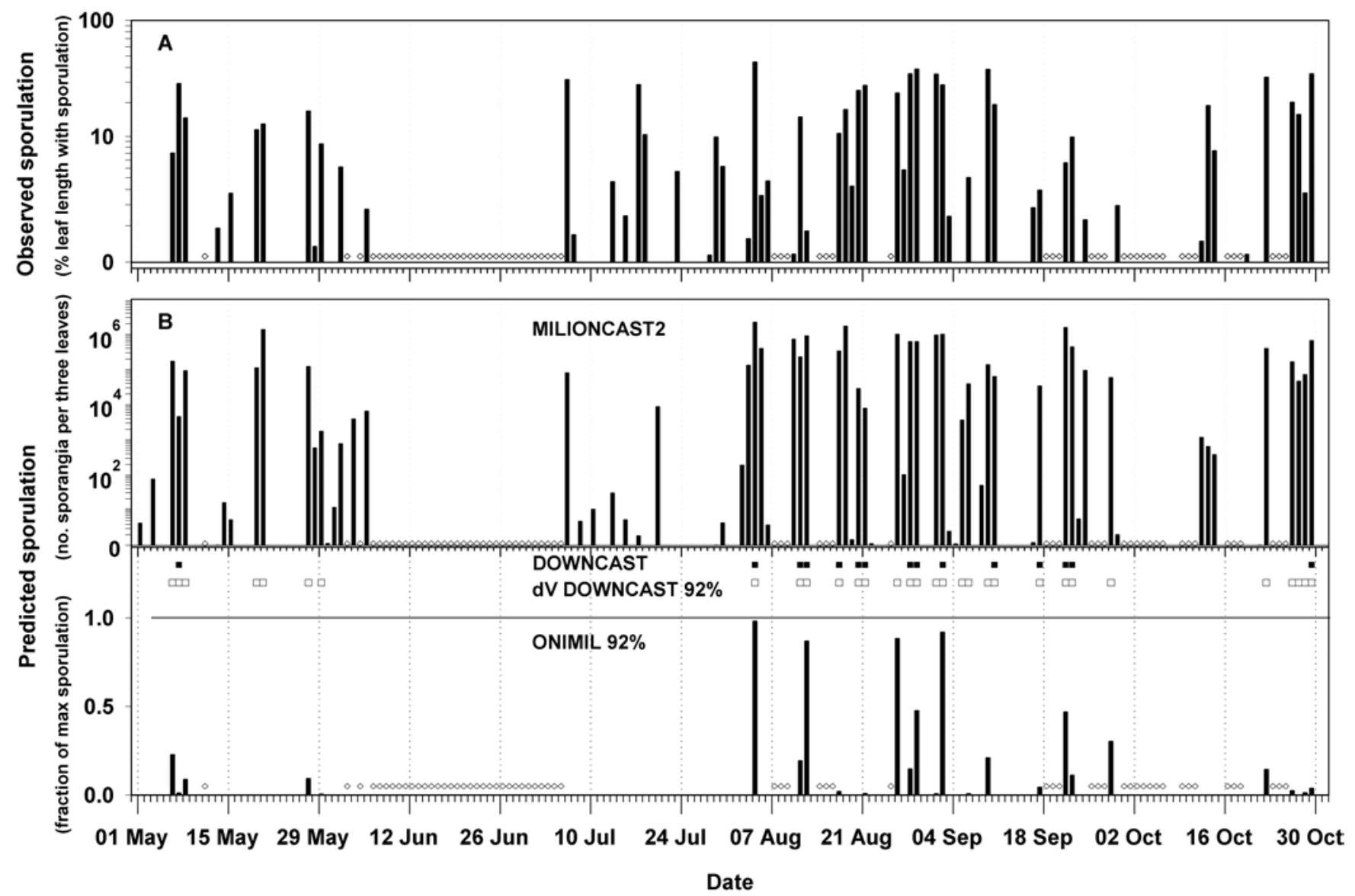

Fig. 4. Temporal patterns of Peronospora destructor sporulation. A, Observed percent leaf length with sporulation from May to October 1999 (vertical bars). B, Predicted sporulation by MILIONCAST2 (vertical bars), DOWNCAST (ם), and de Visser's DOWNCAST (92\% RH threshold) ( $\square$ ), and by ONIMIL (92\% RH threshold) (vertical bars). Days for which no data were collected are indicated $(\diamond)$. 
eases. Pages 375-411 in: Vegetable Diseases and Their Control. The Ronald Press Company, New York.

8. Cook, H. T. 1932. Studies on the downy mildew of onion and the causal organism, Peronospora destructor (Berk.) Caspary. New York Agric. Exp. Stn., Ithaca, Mem. 143:1-40.

9. Cruickshank, I. A. M. 1958. Environment and sporulation of phytopathogenic fungi. IV. The effect of light on the formation of conidia of Peronospora tabacina Adam. Aust. J. Biol. Sci. 16:87-98.

10. Develash, R. K., and Sugha, S. K. 1997. Incidence of downy mildew and its impact on yield. Indian Phytopathol. 50:127-129.

11. de Visser, C. L. M. 1998. Development of a downy mildew advisory model based on downcast. Eur. J. Plant Pathol. 104:933-943.

12. FitzGerald, S. M., and O'Brien, R. G. 1994. Validation of 'Downcast' in the prediction of sporulation-infection periods of Peronospora destructor in the Lockyer Valley. Aust. J. Exp. Agric. 34:537-539.

13. Hildebrand, P. D. 1983. Effects of environmental variables on the infection cycle and epidemiology of Peronospora destructor (Berk.) Casp. in onion. Ph.D. thesis. University of Guelph, Ontario, Canada.

14. Hildebrand, P. D., and Sutton, J. C. 1982. Weather variables in relation to an epidemic of onion downy mildew. Phytopathology 72:219224
15. Hildebrand, P. D., and Sutton, J. C. 1984. Interactive effects of the dark period, humid period, temperature, and light on sporulation of Peronospora destructor. Phytopathology 74:1444-1449.

16. Howell, A. B., and Erwin, D. C. 1995. Characterization and persistence of Verticillium alboatrum isolated from alfalfa growing in hightemperature regions of southern California. Plant Pathol. 44:734-748.

17. Jensen, B. D., Vaerbak, S., Munk, L., and Andersen, S. B. 1999. Characterization and inheritance of partial resistance to downy mildew, Peronospora parasitica, in breeding material of broccoli, Brassica oleracea convar. botrytis var. italica. Plant Breed. 118:549-554.

18. Jesperson, G. D., and Sutton, J. C. 1987. Evaluation of a forecaster for downy mildew of onion (Allium cepa L.). Crop Prot. 6:95103.

19. Kennedy, R., Wakeham, A. J., Byrne, K. G., Meyer, U. M., and Dewey, F. M. 2000. A new method to monitor airborne inoculum of the fungal plant pathogens Mycosphaerella brassicicola and Botrytis cinerea. Appl. Environ. Microbiol. 66:2996-3003.

20. Lang, A. R. G. 1967. Osmotic coefficients and water potentials of sodium chloride solutions from 0 to $40^{\circ}$ C. Aust. J. Chem. 20:2017-2023.

21. Payne, R. W., Baird, D. B., Gilmour, A. R., Harding, S. A., Lane, P. W., Murray, D. A., Soutar, D. M., Thompson, R., Todd, A. D.,
Tunnicliffe Wilson, G., Webster, R., and Welham, S. J. 2000. The guide to Genstat. Part 2 Statistics. VSN International Ltd., Oxford, UK.

22. Rondomanski, W. 1967. Studies on the epidemiology of onion downy mildew, Peronospora destructor (Berk.) Fries. Technical Report for 1962-67. Research Institute for Vegetable Crops, Skierniewice, Poland.

23. van Doorn, A. M. 1959. Onderzoekingen over het optreden en de bestrijding van valse meeldauw (Peronospora destructor) bij uien. Tijdschr. Plantenziekten 65:193-255.

24. Virányi, F. 1981. Downy mildew of onion Pages 461-472 in: The Downy Mildews. D. M. Spencer, ed. Academic Press, New York.

25. Wolfram, S. 1991. Mathematica. A system for doing mathematics by computer. 2nd ed. Addison-Wesley Publishing Company, Redwood City, CA.

26. Wright, P. J., Chynoweth, R. W., Beresford, R. M., and Henshall, W. R. 2002. Comparison of strategies for timing protective and curative fungicides for control of onion downy mildew (Peronospora destructor) in New Zealand. Proc. Br. Crop Prot. Council Conf., Pests Dis. 2002:207-212.

27. Yarwood, C. E. 1937. Relation of light to the diurnal periodicity of sporulation of certain downy mildews. J. Agric. Res. 54:365-373.

28. Yarwood, C. E. 1943. Onion downy mildew. Hilgardia 14:595-691. 